\title{
Programa Future-se: impactos sobre a autonomia das Instituições Federais de Ensino e sobre o direito à educação
}

\author{
Future-se program: impacts on federal education institutions and on \\ the right to higher education
}

\begin{abstract}
Programa Future-se: implicaciones sobre la autonomia de las instituiciones federales de educación y sobre el derecho a la educación superior
\end{abstract}

\section{Filomena Lucia Gossler Rodrigues da Silva ${ }^{1}$}

Instituto Federal de Educação, Ciência e Tecnologia Catarinense, Programa de Pósgraduação em Educação, Professora.

http://orcid.org/0000-0002-8275-7714

Tamiris Possamai

Instituto Federal Catarinense, Servidora. https://orcid.org/0000-0001-6107-1257

Resumo: Este artigo possui como propósito refletir as implicações do Programa Future-se sobre a autonomia das Instituições Federais de Ensino e o direito à educação, neste caso, à educação superior. Para tanto, serão apresentados aspectos do cenário político de ataques aos direitos sociais dos brasileiros, a fim de analisar possíveis desdobramentos, tais como: o uso do Projeto de Lei como instrumento do atual governo para estreitar ainda mais as relações com o setor produtivo e empresarial, restrição da autonomia universitária e alteração das características precípuas e finalidades das universidades e institutos federais. A técnica de pesquisa utilizada foi a análise documental e bibliográfica, de abordagem qualitativa, e parte da compreensão de que as relações sociais são determinadas, historicamente, pelo modo de produção, obstinando a destruição da pseudoconcreticidade (KOSIK, 1976). A análise realizada nos permite afirmar que o Future-se não possui relação com a melhoria da qualidade da educação brasileira, mas vem à reboque das necessidades do capital a fim de obedecer demandas privadas que, em curto prazo, pretendem tornar as Instituições Federais de Ensino lócus de desenvolvimento de pesquisas e produção de conhecimentos comprometidos com a

Doutora em Educação pela Universidade Federal de Santa Catarina; Mestre em Educação pela Universidade do Oeste de Santa Catarina.

2 Bacharela em Direito pelo Centro Universitário para o Desenvolvimento do Alto Vale do Itajaí; mestranda em Educação no Instituto Federal Catarinense. 
lógica da mercadorização da educação, e, portanto, alheia ao desenvolvimento integral dos estudantes e ao pleno gozo do direito à educação.

Palavras-chave: Future-se. Instituições Federais de Ensino. Mercadorização da Educação.

Abstract: This article aims to reflect the implications of Future-se Program on the autonomy of Federal Education Institutions and the right to higher education. To reach this purpose, we present aspects of the political scenario of attacks on Brazilians; social rights and analyze possible outcomes such as: the use of the Bill as an instrument of the current government to further strengthen relations with productive and business sector; the restriction of university autonomy and the alteration of main characteristics and purposes of Universities and Federal Institutes. The research technique used was document analysis and bibliographic review, with a qualitative approach. The reflections start from the understanding that social relations are historically determined by the mode of production, obstinating destruction of pseudo-concrete (KOSIK, 1976). The analysis carried out allows us to affirm that Future-se is unrelated to the improvement of quality of Brazilian education, but comes from capital's needs, in order to comply with private demands that, in short term, intend to make Federal Education Institutions into a locus of research development and knowledge production committed to the logic of the commodification of education, and therefore, unconnected to the integral development of students and the full enjoyment of the Right to education.

Keywords: Future-se. Federal Education Institutions. Commodification of education.

Resumen: Este artículo tiene como objetivo mostrar las implicaciones del 'Programa Futurese' sobre la autonomía de las instituciones federales de educación y el derecho a la educación superior. Para tal propósito presentamos aspectos del escenario de los brasileños y analizamos posibles desdobramientos como: el uso del proyecto de ley como instrumento del gobierno actual para fortalecer aún más las relaciones con el sector productivo y empresarial; la restricción de la autonomía universitaria y la alteración de los principales principios y propósitos de las universidades e institutos federales. La metodología de investigación fue el análisis de documentos y la revisión bibliográfica, con enfoque cualitativo. Las reflexiones parten de la comprensión de que las relaciones sociales están históricamente determinadas por el modo de producción, obstinando la destrucción de la pseudoconcreción (KOSIK, 1976). El análisis realizado nos permite establecer que Future-se no está relacionado con la mejora de la calidad de la educación brasileña, sino que va acompañado de las necesidades del capital para cumplir con demandas privadas que, en el corto plazo, pretende hacer que las instituciones federales de educación en el lugar de desarrollo de la investigación y producción de conocimiento comprometido con la lógica de la mercantilización de la educación y, por lo tanto, ajeno al desarrollo integral de los estudiantes y al pleno disfrute del derecho a la educación.

Palabras-clave: Future-se. Instituciones Federales de Educación. Mercantilización de la educación. 


\section{INTRODUÇÃO}

0 Projeto de Lei que institui o Programa Universidades e Institutos Empreendedores e lnovadores - Future-se - já foi apresentado em três versões. Desde sua primeira versão, apresentada pelo Ministério da Educação em 17 de junho de 2019, ele vem gerando muita discussão entre os pesquisadores de políticas educacionais, gestores das Instituições Federais de Ensino (IFEs) e interessados de modo geral.

Para contribuir com as análises e considerações sobre a proposta apresentada pelo governo federal, no presente artigo, objetivamos refletir as implicações do Programa Future-se sobre a autonomia das Instituições Federais de Ensino e o direito à educação, que, neste caso específico, refere-se à educação superior. Para tanto, iniciamos apresentando o atual cenário político no qual foi gestado o Projeto de Lei que, de forma inequívoca, tem atacado direitos sociais. Quando falamos de ataques a direitos sociais pressupomos que, por ser a classe trabalhadora a maior impactada por eles, os ataques são à classe trabalhadora. Isso porque, especialmente a essa classe pertencem os indivíduos que usufruem e necessitam dos serviços públicos ofertados pelo Estado brasileiro.

0 Future-se promete, tal como se apresenta, constituir-se em uma alternativa de financiamento de atividades das IFEs, prevendo formas de captar recursos próprios. No entanto, para que isso aconteça, exige contrato de gestão com Organizações Sociais (OSs) e contrato de desempenho ou resultados (metas e resultados) com a União, constitui um comitê gestor para supervisionar as atividades, entre outros mecanismos que ameaçam a autonomia didático-científica, administrativa e de gestão financeira e patrimonial. Além disso, vale mencionar que os três eixos principais do Future-se condicionam as IFEs a um estreitamento das suas relações com o setor produtivo e empresarial, implicando em uma progressiva desresponsabilização do Estado sobre o financiamento da educação.

Tendo presente o exposto nesta introdução, este artigo se divide, além da introdução e das considerações finais, em duas partes. Na primeira, buscamos apresentar aspectos do cenário atual brasileiro de ataques a direitos sociais, destacando-se o crescimento exponencial das Redes Privadas de Educação Superior; o "Novo Regime Fiscal no âmbito dos Orçamentos Fiscal e da Seguridade Social da União", que vigorará por 20 exercícios financeiros a partir de 2016, que se materializa por meio da Emenda Constitucional n. 95; as Reformas Trabalhista, Previdenciária e do Ensino Médio e, com eles, o cenário apropriado para apresentar uma "reforma" no Ensino Superior, o Future-se. Na segunda parte, descrevemos a movimentação do Ministério da Educação que apresentou, até janeiro de 2020, três versões do Projeto de Lei que institui o Future-se. Os recortes feitos, das três versões do Projeto de Lei, buscam demonstrar os principais problemas encontrados nos textos. Não propomos 
fazer uma análise ponto a ponto, mas, problematizando partes importantes do texto, fazer uma análise coerente a partir da realidade concreta em que a proposta de apresenta.

\section{METODOLOGIA}

Em termos teórico-metodológicos, utilizamos, para desenvolver o presente artigo, a técnica de pesquisa de análise documental, especialmente das três versões do Projeto de Lei, ainda sem número, que dispõe sobre o Programa Future-se, além dos demais textos legais que positivam direitos sociais. Também, de pesquisa bibliográfica para fundamentar as reflexões e considerações sobre as categorias principais da discussão, tais como política educacional, ataques a direitos sociais, ameaça à autonomia das IFEs, mercadorização da educação e fenômenos relacionados.

Com abordagem qualitativa e, necessariamente, crítica, partimos da compreensão de que as relações sociais são determinadas pelo modo de produção capitalista e que elas não expressam, imediatamente, a essência de seus fenômenos. Conforme Kosik (1976), o complexo dos fenômenos que habitam o ambiente cotidiano, com sua regularidade, evidência e imediatismo que penetram na consciência dos indivíduos, constitui o mundo da pseudoconcreticidade, no qual seu elemento próprio é o duplo sentido. Isso porque "o fenômeno indica a essência e, ao mesmo tempo, a esconde. A essência se manifesta no fenômeno, mas só de modo inadequado, parcial, ou apenas sob certos ângulos e aspectos." (KOSIK, 1976, p. 15). Para a destruição da pseudoconcreticidade - que é o processo de criação da realidade concreta -, propomo-nos perseguir, com o rigor necessário, a essência que se manifesta no Programa Future-se, mas não se revela imediatamente.

\section{O ATUAL CENÁRIO BRASILEIRO DE ATAQUES À CLASSE TRABALHADORA}

Partindo do princípio de que nenhuma política educacional pode ser analisada e compreendida fora do contexto em que é implantada, entendemos que o Future-se precisa ser apreendido como expressão de formas de Estado, relações jurídicas, ideologias e contextos sócio-históricos. Assim, a análise necessária para entender a lógica da retirada da perspectiva da educação como direito humano presente no Programa Future-se implica lançar o olhar para além da sua aparência propositalmente fabricada pelo governo. Ou seja, 
é imprescindivel que compreendamos o Programa considerando as formas de produção da vida e sua correspondente relação social de produção (MARX, 1986).

É evidente que nada do que foi conquistado, pela e para a classe trabalhadora brasileira, foi benesse de políticas públicas em governos anteriores; pelo contrário, foi com muita luta que pesquisas e políticas educacionais foram construídas e estabeleceram, em alguma medida, resistências às retiradas de direitos. No entanto, é especialmente nos últimos quatro anos que observamos a maior retirada de direitos sociais brasileiros historicamente conquistados após a Constituição Federal de 1988.

Porém, é preciso ir mais longe para buscar elementos capazes de subsidiar as discussões sobre as medidas de desmanche das políticas públicas do ensino superior que hoje são observadas. Após a promulgação da Constituição da República Federativa do Brasil de 1988 foi plantada uma semente que fundamenta a execução de atividades lantes puramente estatais), pelo Terceiro Setor. A Lei n. 9.637/98, utilizada hoje para permitir que Organizações Sociais sejam as responsáveis pela gestão de instituições públicas, foi criada, não por acaso, em um governo caracterizado por um projeto político e econômico neoliberal que instituiu o Programa de Publicização para alterar o padrão estatal-público para o padrão público-privado (SANTOS, 2017). Santos (2017, p. 5) argumenta que:

\footnotetext{
No contexto de Contrarreforma do Estado, onde se passa a mercantilizar os direitos sociais e entregar a execução de seus bens e serviços às organizações públicas não estatais, o Programa Nacional de Publicização instituído pela Lei Federal $n^{\circ}$ 9637/98, prevê a criação das agências executivas e organizações sociais, além da regulamentação do terceiro setor (entidades públicas não estatais regidas pelo direito civil privado) para a execução de políticas públicas passando de Estado-provedor a um Estado com forte influência do mercado [...]
}

0 padrão instituído, inaugurado com a Lei mencionada, durante os governos que a sucederam, não foi abandonado ou revogado. Diferentemente disso, embora com propósitos distintos dos atuais, foi largamente utilizado, inclusive para desenvolver programas de promoção e democratização do acesso ao ensino superior que marcam os governos do Partido dos Trabalhadores. Em que pese serem inegáveis a expansão e a interiorização das Universidades Públicas e Institutos Federais, esse crescimento ocorreu também, fomentado pelo Estado, na rede privada de ensino superior. Segundo destacam Seki, Souza e Evangelista (2017, p. 458), "a desregulamentação do ensino superior brasileiro e sua respectiva liberalização criou amplas condições para a ampliação do setor privado."

Analisando as Sinopses Estatísticas da Educação Superior, disponiveis no portal do Instituto Nacional de Estudos e Pesquisas Educacionais Anísio Teixeira (INEP), os Censos 
de 2002, 2010 e 2017 revelam que as Instituições Públicas Federais eram 73, 99 e 109, respectivamente. Enquanto as Instituições Privadas eram $1.442 \mathrm{em} 2002$, aumentaram para $2.100 \mathrm{em} 2010 \mathrm{e}$ em 2017, eram 2.152 (INSTITUTO NACIONAL DE ESTUDOS E PESQUISAS EDUCACIONAIS ANíSIO TEIXEIRA, 2002, 2010, 2017). Se, por um lado, a política de democratização do acesso ao ensino superior ampliou as condições de acesso da população a níveis mais elevados de estudo, por outro, atraiu grupos e interesses do mercado educacional e oportunizou o avanço da hegemonia capitalista na formação superior. A Rede Privada (majoritariamente instituições particulares), por ter recebido fomento público, aumentou em muito o número de instituições, cursos e matrículas.

Outro aspecto importante a ser mencionado é o fato de que o investimento em instituições públicas e políticas voltadas para a ampliação do acesso com qualidade no ensino superior foram insuficientes para competir com a expansão das instituições particulares, também fomentadas pelo Estado. Com esse modus operandi da gestão das politicas públicas de ensino superior, as instituições privadas viram o mercado educacional tornar-se um filão de mercado lucrativo. Os estudantes, por sua vez, apesar de muitas vezes terem que lidar com o endividamento "a perder de vista", pois "outra crueldade subjaz à sanha privatizante [..] trata-se do endividamento massivo da juventude brasileira, seja mediante programas como FIES, seja de financiamentos privados. Nos dois casos, são dívidas contraidas individualmente" por jovens que (SEKI; SOUZA; EVANGELISTA, 2017, p. 462) viram esse mercado educacional chegar até suas casas por uma modalidade pouco custosa a quem oferta, a modalidade a distância.

0 fenômeno da expansão do ensino superior privado, fomentado com verba pública, aponta que "[...] o fato objetivo da expansão e concentração de cursos e matrículas nas privadas coaduna-se à hipótese de que houve uma mudança de fundo na estrutura da educação superior brasileira que vem sendo chamada de financeirização do capital [...." (SEKl; SOUZA; EVANGELISTA, 2017, p. 459). Além disso,

\footnotetext{
Os cursos de licenciatura, considerados baratos quando comparados aos que exigem laboratórios, técnicos especializados, instalações específicas, máquinas e equipamentos e outros requisitos legais, acabaram por figurar como verdadeiras "máquinas de fazer matrícula", especialmente para as grandes escolas particulares, ou seja, instituições de direito privado com fins lucrativos. (SEKI; SOUZA; EVANGELISTA, 2017, p. 459).
} 
Também, acerca da formação dos professores, os "capitais estrangeiros americanos, europeus, australianos - detêm cada vez mais as rédeas dos formatos e conteúdo da formação do magistério brasileiro. Encontramo-nos frente a frente com o projeto educativo do capital, isto é, o capital como educador do educador." (SEKI; SOUZA; EVANGELISTA, 2017, p. 463). Os fenômenos que procuram mercadorizar a educação podem ser compreendidos a partir de dois conceitos formulados por Rodrigues (2007 apud SEKI; SOUZA; EVANGELISTA, 2017, p. 458): mercadoria-educação e educação-mercadoria:

\footnotetext{
0 primeiro sugere que a educação funciona como insumo para a constituição de uma outra mercadoria, qual seja, a força de trabalho, relacionando-se à necessidade de reordenamento entre as relações técnicas da produção e a qualificação dos trabalhadores. [...] A segunda forma, educação-mercadoria, entende a educação como mercadoria produzida e disponibilizada nas gôndolas do mercado, dizendo respeito à educação privada.
}

A tendência é que a educação se torne uma mercadoria cada vez mais lucrativa aos grupos privados, e é nessa conjuntura de ataques intensificados a direitos historicamente conquistados pela e para a classe trabalhadora que, em seu primeiro ano de mandato, a equipe de governo do Presidente da República, eleito em 2018, anunciou pelo menos três contingenciamentos de verbas dos ensinos básico e superior (Instituições Públicas de Ensino) e apresentou, recentemente, um programa para que essas instituições captem recursos próprios e alterem, substancialmente, seu papel social: o Programa Future-se.

Importa mencionar, fazendo um recorte do pós-impeachment da primeira Presidenta do Brasil, que a Emenda Constitucional n. 95, aprovada em 2016, alterou a Constituição Federal e instituiu "o Novo Regime Fiscal no âmbito dos Orçamentos Fiscal e da Seguridade Social da União, que vigorará por vinte exercícios financeiros" (BRASIL, 2016) e que ela, de forma inequívoca, materializa-se em uma medida de precarização dos serviços públicos por 20 anos.

Outro elemento essencial para nossa análise de ataques aos direitos sociais dos brasileiros, que provoca a diminuição do Estado e das proteções sociais, é a aprovação da Reforma Trabalhista (Lei n. 13.467/2017), que alterou substancialmente a Consolidação das Leis Trabalhistas (CLT) e apareceu para a população como uma promessa para acabar com o desemprego e tirar o País da crise. Além disso, após a posse do Presidente eleito em 2018, Jair Messias Bolsonaro, houve um agravamento significativo da precarização dos direitos trabalhistas com a extinção do Ministério do Trabalho e desmonte de toda sua estrutura, que hoje é apenas uma Secretaria alocada no Ministério da Economia.

Por fim, os parlamentares aprovaram uma reforma da Previdência proposta pelo governo federal - como parte da sua agenda austera de retirada de direitos individuais e 
coletivos. A Reforma, que desestrutura o sistema de Previdência Social, também atinge a Saúde e a Assistência Social, pois, juntos, compõem o tripé da Seguridade Social. Dessa forma, com o ataque a um dos pilares da Seguridade Social, essa Reforma representa uma ameaça aos campos que amparam e garantem um mínimo de dignidade a milhões de brasileiros. É a Emenda Constitucional n. 103, de 12 de novembro de 2019.

No tocante à Educação Básica, é nesse cenário de ataques que esse direito social, como os demais já mencionados, também se torna alvo. Uma das primeiras Medidas Provisórias ${ }^{4}$ emitidas pelo Vice-presidente que assumiu o governo após o impeachment presidencial em 2016 foi a MP n. 746. No ano seguinte, tal MP transformou-se na Lei $n$. 13.415/2017 que, como resultado, alterou a Lei de Diretrizes e Bases da Educação Nacional (LDB - Lei n. 9.394/96), impactando fortemente a organização e as finalidades do Ensino Médio e a Lei n. 11.494/2007, que regulamenta o Fundo de Manutenção e Desenvolvimento da Educação Básica e de Valorização dos Profissionais da Educação (Fundeb). A Reforma, desde sua apresentação por meio de instrumento Presidencial, que deveria ser utilizado somente em casos de relevância e urgência, negligenciou o debate amplo e não ouviu os principais interessados e foi incansavelmente questionada, principalmente por parte de associações ${ }^{5}$ de intelectuais da educação, sindicatos de trabalhadores da educação, entre outros, ressaltando que as alterações produzidas impactam direitos de milhões de estudantes e trabalhadores da educação. Ao analisar o texto da Reforma do Ensino Médio,

\footnotetext{
[...] a atual reforma está sustentada na defesa da necessidade de adequação do ensino médio a requisitos postos pelo mercado de trabalho e/ou por necessidades definidas pelo setor empresarial. Tal defesa aproxima a última etapa da educação básica a uma visão mercantil da escola pública e adota critérios pragmáticos para definir os rumos da mudança [...] (SLLVA; SCHEIBE, 2017, p. 21).
}

Como desdobramentos dessa Reforma, Araujo (2019, p. 54) prevê alguns impactos, como "a ampliação dos processos de exclusão dos jovens de origem trabalhadora, o aprofundamento das desigualdades, a redução do papel das escolas como fator de geração de oportunidades sociais [...] le o] crescimento exponencial dos processos de privatização da educação básica." 
A Reforma do Ensino Médio ainda tem causado reestruturações no ambiente escolar, com a necessária reorganização curricular e a adequação de políticas institucionais, uma vez que será competência das instituições federais de ensino que ofertam essa etapa da formação, dos estados e do Distrito Federal decidir sobre seus sistemas de ensino, conforme disponibilidade e interesse - atentando-se à Base Nacional Comum Curricular (BNCC) e às Diretrizes Curriculares Nacionais para o Ensino Médio. Por fim, é preciso destacar que “[...] a leitura cuidadosa da Lei permite compreender que ela não é propriamente uma reforma educacional, mas parte de um processo de desregulamentação, precarização e desagregação do ensino médio e de outros espaços públicos." (KRAWCZYK; FERRETTI, 2017, p. 41).

Apresentado este contexto, podemos compreender que, embora as disputas no campo educacional não sejam novidades, nestes últimos anos é possível observar um aceleramento do processo de mercadorização da educação, em que grupos buscam lucrar com esse direito de todos e dever do Estado. Não descolado dessa realidade, o Ensino Superior Público também vem sendo desqualificado, precarizado e alvo de ataques contra seu papel social de formação humana, para além da lógica e demanda do mundo das mercadorias.

\section{O PROGRAMA FUTURE-SE: AUTONOMIA DAS INSTITUIÇÕES DE ENSINO E DO DIREITO À EDUCAÇÃO EM RISCO}

Inicialmente, a proposta anunciada pelo Ministério da Educação, em 17 de julho de 2019, e o Projeto de Lei (PL) que a materializa foram disponibilizados em uma plataforma, lincados ao portal do Ministério da Educação, onde o Future-se, em destaque, esteve aberto para consulta pública. Primeiramente, tal consulta seria finalizada em 15 de agosto, mas acabou sendo prorrogada até o dia 29 desse mesmo mês, tentando garantir uma roupagem de debate democrático e participativo. Após reapresentação, em outubro de 2019, apontamentos e diversas manifestações das Instituições Federais de Ensino rejeitando o Programa seguiram denunciando o teor do projeto. Em 3 de janeiro de 2020 o Projeto de Lei foi publicado no Diário Oficial da União (DOU) ${ }^{6}$ juntamente ao despacho do Ministro de Estado Chefe da Casa Civil, Onyx Lorenzoni, anunciando abertura de consulta pública sobre a matéria. Para sugerir alterações era possível enviar correio eletrônico ou acessar sítio eletrônico criado para esse fim, até 24 de janeiro de 2020. ${ }^{7}$ Trataremos a primeira versão como V1, o texto reapresentado em outubro de 2019 como V2, e a versão publicada no Diário Oficial da União como V3.

Publicado em: 03/01/2020, edição: 2, seção: 1, página 1, Órgão: Presidência da República/Casa Civil.

0s endereços eletrônicos são, respectivamente, futureseconsulta@mec.gov.br e http://www.participa.br/future-se. 
Segundo justificativa da equipe do governo federal, o Programa foi pensado para fortalecer o ensino superior, criando mecanismos para captação de recursos próprios e formas alternativas de financiamento de atividades dessas instituições, uma vez que estas se encontram em crise tendo em vista seu alto custo aos cofres públicos. Assim, seriam necessárias medidas como as apresentadas no Future-se para o equilibrio das contas e recuperação do crescimento econômico. No entanto, a apresentação já dava pistas de quem são os principais envolvidos e interessados no texto, ao expressar que "A proposta aqui apresentada é um documento em construção que só estará finalizado com a participação da sociedade brasileira, sobretudo dos estudantes, professores e empresários do nosso País."8 (BRASIL, 2019b, grifo nosso). Depois de passado o período da primeira consulta pública, análise das contribuições e análise de técnicos nomeados pelo MEC, o anteprojeto foi reapresentado em outubro de 2019, com alguns aspectos aparentemente alterados, mas que manteve, substancialmente, a concepção apresentada em sua primeira versão. Já em 3 de janeiro de 2020, o projeto publicado no DOU conta com redução significativa de artigos, mas ínfimas alterações no conteúdo.

É importante pontuar, a partir de uma análise da realidade concreta, que não é em qualquer conjuntura que se propõe um programa como o Future-se, porque tal proposta só é apresentada quando, após ser gestada por longo prazo, criam-se narrativas de esgotamento orçamentário, desqualificação e omissão dos resultados, desvalorização de todo o processo de construção das políticas construídas, ataques aos professores universitários e aos acadêmicos desses espaços e articulação de lobby ${ }^{9}$ nas instâncias legislativas para garantir a tramitação de tais propostas.

0 Projeto de Lei institui o Programa Universidades e Institutos Empreendedores e Inovadores - Future-se - e prevê, em sua versão publicada no DOU, os seguintes objetivos:

\footnotetext{
I - incentivar fontes privadas adicionais de financiamento para projetos e programas de interesse de universidades e institutos federais; II - promover e incentivar o desenvolvimento científico, a pesquisa, a capacitação científica e tecnológica e a inovação; III - fomentar a cultura empreendedora em projetos e programas destinados ao ensino superior; IV - estimular a internacionalização das universidades e dos institutos federais; e V aumentar as taxas de conclusão e os índices de empregabilidade dos egressos de universidades e institutos federais. ${ }^{10}$
} 
Ou seja, o objetivo principal é incentivar que as Universidades e Institutos Federais busquem, alternativamente ao Estado, fontes para captar recursos a fim de financiar suas atividades. Nenhum dos objetivos previstos manifesta preocupação com aspectos qualitativos da educação ou fortalecimento das Instituições Federais de Ensino (IFEs) como bens públicos e, por essa omissão, expressa um sentido preocupante quando possibilita formas de privatizar parte das atividades institucionais. Isso porque,

\begin{abstract}
Nos encaminhamentos políticos da atualidade, o termo privatização encontra-se relacionado a múltiplas e diferentes formas que, direta ou indiretamente, ao mesmo tempo em que se alinham às novas oportunidades de negócios e de lucro, têm influenciado as agendas, a tomada de decisões, a gestão pública e o processo de desencargo do Estado, que delega a outras instâncias grande parte de suas funções sociais. (PERONI; CARVALHO, 2019, p. 1).
\end{abstract}

Privatizar, hoje, não se restringe a um único modelo de desestatização, e transferir a gestão, que também é um campo estratégico das universidades e institutos federais, a uma Organização Social, como prevê o Programa, também pode configurar uma espécie dela.

Em sua primeira versão, o PL trazia três eixos principais: Eixo 1: Governança, Gestão e Empreendedorismo; Eixo 2: Pesquisa, Desenvolvimento e Inovação; e Eixo 3: Internacionalização. Após o prazo de consulta pública e ajustes, a V2, reapresentada em outubro de 2019, trouxe pouca alteração nos eixos, compreendendo: "I - pesquisa, desenvolvimento tecnológico e inovação; || - empreendedorismo; || - internacionalização", tirando do texto, com isso, governança e gestão (BRASIL, 2019c). A V3, publicada no DOU em janeiro de 2020, mantém os três eixos previstos na V2.

A grande defesa do governo é tornar as Universidades Públicas e os Institutos Federais espécies de núcleos empreendedores e utilizar toda a estrutura (física, trabalhadores e estudantes) para a produção de pesquisas e produtos para atender demandas, tão somente, do mercado do capital. 0 fato de o tripé ensino, pesquisa e extensão, os processos formativos, a valorização dos trabalhadores e as melhorias nas condições de trabalho ou na qualidade da formação não aparecerem como preocupações do Programa nos coloca em alerta.

No texto do PL publicado no DOU (V3), observamos que o termo "empreendedorismo" e variáveis como empreendedora/empreendedores aparecem 13 vezes; "produto" aparece seis vezes; "contrato de resultado", 15 vezes; "contrato de gestão", 10 vezes; e "investimento", seis vezes. Já "sustentável" aparece uma vez; "inclusão" só aparece para prever inclusão de conteúdos e atividades de empreendedorismo nas matrizes curriculares, e "qualidade", só para tratar de "produtos com qualidade". A ausência de alguns termos e categorias pode expressar que foram esquecidos ou que são desconsiderados e até negados. No caso, 
- Programa parece desconsiderar e negar que as Universidades e os Institutos Federais formem humanos em todas as áreas do conhecimento.

A V2 do PL trouxe novidades ao prever que entre a Instituição de Ensino e a União (via MEC) seria ajustado um "contrato de desempenho" (BRASIL, 2019c). Já na V3, substitui-se "contrato de desempenho" por "contrato de resultado", em que a Universidade ou o Instituto Federal que pretender participar do Programa Future-se celebrará contrato de resultado com a União, intermediado pelo Ministério da Educação (BRASIL, 2020). 0 art. $6^{\circ}$ da V3 prevê que a celebração do contrato terá como contrapartida a concessão de benefícios por resultado. Além disso, em seu $§ 2^{\circ}$,

Os beneficios por resultado compreendem o recebimento de recursos provenientes do Fundo de Investimento do Conhecimento, a possibilidade de aporte patrimonial das instituições participantes a esse Fundo e de recursos orçamentários adicionais consignados ao Ministério da Educação e a concessão, preferencial, de bolsas da Coordenação de Aperfeiçoamento de Pessoal de Nivel Superior - Capes aos participantes de Programa Future-se.

Primeiro ponto é que as consequências e os desdobramentos decorrentes do não alcance das metas estabelecidas, por parte das Universidades ou Institutos Federais, não estão expressos no texto. Seriam penalizadas as instituições de ensino a não receberem recursos que são delas? 0 art. 13 prevê que, quando descumpridas as disposições contidas no contrato de resultado, a Universidade ou Instituto Federal será desligado do Programa Future-se e que esse desligamento suspenderá o recebimento dos benefícios previstos, mas não diz como, por qual período ou quais serviços da instituição de ensino seriam prejudicados pelo não cumprimento das metas avençadas. Essa lógica de "estabelecimento de metas, avaliação sistemática do rendimento escolar, responsabilização individual pelo sucesso ou fracasso ampliou o domínio dos resultados sobre o processo, reduzindo o trabalho educativo ao produto, num movimento fetichista bastante conhecido." (CATINI, 2019, p. 35). 0 empreendedorismo é o pano de fundo.

Outro aspecto importante a ser mencionado é que priorizar a concessão de bolsas da Capes às instituições de ensino participantes do Future-se desrespeita o princípio da impessoalidade, que, inclusive, é previsto no art. $2^{\circ}$ da V3, assim como na Constituição Federal de 1988, é fomentar a produção de conhecimentos que se alinhem com a política defendida pelo Programa, atrelando as atividades de pesquisa das instituições públicas a interesses privados, agredindo a autonomia didático-científica, também prevista na Carta Magna de 1988.

Outra figura questionável que reaparece na V3, após ter sido excluída na V2, é o comitê gestor. 0 art. $9^{\circ}$ traz que " 0 Programa Future-se será acompanhado e supervisionado 
por comitê gestor, com composição e funcionamento definidos em regulamento", sendo garantida a participação de representantes das universidades e institutos federais e dos Ministérios da Economia, da Educação, e da Ciência, Tecnologia, Inovações e Comunicações (BRASIL, 2020, art. 9०, I a IV). Em outras palavras, ainda sem regulamento que disponha sobre seu funcionamento, o comitê gestor terá poderes para decidir sobre assuntos concernentes ao Programa, acompanhar, supervisionar e avaliar o desempenho e resultados das instituições de ensino, caracterizando uma forma de minar qualquer autonomia didáticocientífica, administrativa e de gestão financeira e patrimonial previstas e garantidas pela Constituição Federal às Instituições.

0 PL traz que as IFEs celebrarão contrato de gestão com Organizações Sociais (OSs) "para executar as atividades previstas nos eixos do Future-se" (BRASIL, 2020, art. 14), corroborando a ideia de transferir uma responsabilidade que é do Estado ao Terceiro Setor. Ao citar obediência à autonomia universitária, o art. $2^{\circ}$, l, do PL parece contradizer a totalidade do texto, uma vez que a captação de recursos próprios, expressamente prevista no PL, poderá condicionar o recebimento de valores e benefícios ao oferecimento de pesquisas e resultados esperados, tão somente, por seus financiadores. Ou é possível acreditar que haverá recurso e financiamento privados para subsidiar cursos e pesquisas que caminhem na contramão dos interesses do capital, que permitam uma formação integral e que compreendam a necessidade da transformação social como fator determinante para a emancipação dos sujeitos?

Conforme previsto nas três versões do PL, uma Organização Social (OS) poderá ser a parte incumbida de gerir atividades da Instituição Federal de Ensino, em que a relação jurídica será celebrada via contrato de gestão diretamente com a Universidade ou Instituto Federal. Como parte do Terceiro Setor (Pessoas Jurídicas de Direito Privado, sem fins lucrativos, que exercem atividades de interesse público), as OSs são entidades privadas (associações ou fundações) habilitadas pelo Poder Executivo que observam a Lei n. 9.637/1998 e ajustam, por meio de um contrato, a administração de atividades ligadas ao "[...] ao ensino, à pesquisa científica, ao desenvolvimento tecnológico, à proteção e preservação do meio ambiente, à cultura e à saúde." (BRASIL, 1998, art. 1).

Se considerarmos que o Decreto n. 9.262, de 9 de janeiro de 2018," extinguiu vários cargos dos quadros de pessoal da administração pública federal, inclusive cargos técnicos administrativos em educação de Universidades e Institutos Federais, transferir qualquer espécie de gestão administrativa das IFEs a uma entidade externa (OS) implicaria colocar em risco os demais cargos de técnicos administrativos em educação que exercem

0 Decreto n. 9.269, de 9 de janeiro de 2018, emitido pelo ex-Presidente da República Michel Temer, "extingue cargos efetivos vagos e que vierem a vagar dos quadros de pessoal da administração pública federal, e veda abertura de concurso público e provimento de vagas adicionais para os cargos que especifica." (BRASIL, 2018). 
funções administrativas? Ao contrário do que diz a proposta, o exercício pleno da autonomia administrativa e de gestão, mais uma vez, será ameaçado, visto que a oferta e as atividades de pesquisa estarão atreladas, de forma preponderante, senão exclusivamente, às demandas dos "financiadores".

0 PL prevê, ainda, que a Universidade ou Instituto Federal poderá celebrar contratos e firmar convênios com Fundações de Apoio (BRASIL, 2020, art. 14). Nesse aspecto, o PL não traz nenhuma novidade porque essa possibilidade de convênio já existe e, inclusive, é realidade em várias Universidades e Institutos Federais. Logo, não há necessidade de um novo programa para permitir que isso aconteça.

Como já caracterizado na introdução do texto, o empreendedorismo é um dos eixos do programa, e o art. 20 trata de estabelecer suas diretrizes, assim como admite a criação de Sociedade de Propósito Específico (SPE). A SPE é uma sociedade empresarial com atividade definida e limitada, para desenvolvimento de pesquisas e produtos no interior das Instituições, que deverá obedecer a padrões de governança corporativa. 0 PL deixa claro, ainda, que pretende focar em parcerias com o setor empresarial, apoiando a criação de empresas juniores (art. 20, V), fomentando projetos de pesquisa e de inovação que estimulem o surgimento de empresas e startups para atenderem necessidades de mercado lart. 20, VII) e promovendo ações de empregabilidade e empreendedorismo para os estudantes (art. 20, VIII), reduzindo, assim, a formação ofertada a uma promessa de emprego. Dispõe, em seu art. 21, que "0 Ministério da Educação fomentará a construção de plataformas tecnológicas para promover a aproximação constante entre as universidades, os institutos federais e o setor produtivo, com vistas à inovação e ao empreendedorismo nacional." (BRASIL, 2020). Parece combinar com outros fatores que, ao introduzirem o empreendedorismo no trabalho educativo, ensinam que é natural aderir à competitividade para sobreviver e, com isso, criar uma consciência via assimilação individual da ideologia (CATINI, 2019).

Importa destacar que, com a incapacidade de absorção da força de trabalho ativa nas condições de assalariamento, estrutura-se "um novo paradigma de emprego mais flexível, precário e destituído das garantias sociais [...] Em consequência disto, o surgimento da visão empreendedora de mercado, que parece ser uma estratégia para a superação da crise, da informalidade, do desemprego" (SILVA; TEIXEIRA, 2015, p. 628) e constitui-se, assim, um novo fetiche do capital (SILVA; TEIXEIRA, 2015).

Com os altos índices de desemprego, a informalidade surge como fator funcional ao capital e assume uma imagem ilusória de opção de trabalho associada ao empreendedorismo (SILVA; TEIXEIRA, 2015). Esse novo padrão, exigido pelo capital e ratificado pela educação empreendedora, no viés neoliberal, resigna o trabalhador aos piores cenários de desemprego e desproteção social, transfere responsabilidades do Estado ao indivíduo e glamourizada as condições mais precárias de vida e de trabalho. 
Ainda no Capítulo V, sobre o eixo do empreendedorismo, o PL (V3) traz a possibilidade de celebração de contratos de concessão de direito de nomear móveis, imóveis, lugares ou eventos para "exploração econômica" em troca de coisa economicamente mensurável (BRASIL, 2020, art. 22). Tal aspecto permite que marcas e nomes estampem os bens patrimoniais e eventos da Instituição Federal de Ensino, numa preocupante afronta, novamente, a um dos princípios constitucionais da Administração Pública, a saber, a impessoalidade.

Já no capítulo seguinte do PL, a internacionalização, que é o eixo 3 do Programa, ele também expressa o ideário da meritocracia - associada ao empreendedorismo - quando prevê formas de melhores oportunidades e premiações aos estudantes que apresentarem melhor desempenho individual. A categoria internacionalização diz respeito à solidariedade e à interculturalidade, e a transnacionalização, geralmente, está relacionada a processos de mercadorização da educação superior (AZEVED0, 2015). Faz mais sentido que o texto, pelo teor de sua totalidade, apesar de prever internacionalização, traga o fenômeno da transnacionalização, que se constitui em uma "oferta transfronteiriça de ensino, presencial ou a distância, por intermédio de organizações transnacionais de serviços educacionais com finalidade de lucro." (AZEVED0, 2015, p. 87).

Atentando-nos à diferenciação dos conceitos e fenômenos, é possível compreender que o termo internacionalização, que não é deslocado, mas parte de um projeto, não manifesta sua real intencionalidade. Desse modo, para analisarmos a totalidade da proposta, assim como para entendermos as políticas desse governo, é preciso desvelar a pseudoconcreticidade (KOSIK, 1976), a manifestação que não reflete a essência da proposta, uma vez que a precarização da oferta pública de educação superior caminha a passos largos e o PL corrobora com a ideia de mercadorização quando propõe lógicas empresariais no interior de nossas IFEs. Essa lógica provocará, inevitavelmente, tensões que são próprias do mundo das mercadorias (AZEVED0, 2015).

No texto da V3, a lógica que responsabiliza apenas o indivíduo por seus resultados, que desconsidera todos os outros fatores historicamente determinados e determinantes se expressa quando promete, no seu Art. 25, XXII, "[...] incentivo à concessão de bolsas de estudo para discentes com alto desempenho acadêmico ou atlético." (BRASIL, 2020). E, além disso, não se compromete ou ratifica a necessidade de políticas e ações afirmativas para os grupos socioeconomicamente vulneráveis, a fim de garantir o acesso, a permanência e o êxito dessas parcelas da classe trabalhadora, prevendo apenas a valorização e o incentivo aos melhores desempenhos. A lógica presente no Future-se, com isso, fomenta a competitividade e desestimula a necessária compreensão do ambiente universitário como lugar de processos colaborativos para a produção do conhecimento. Propõe, portanto, o individualismo e o aumento das desigualdades históricas que vinham sendo desconstruídas 
nesses espaços, e buscando uma educação aniquiladora da experiência formativa e da autonomia (CATINI, 2019).

Até a V2, o texto trazia dois fundos de investimento expressamente previstos, o Fundo Patrimonial do Future-se e o Fundo Soberano do Conhecimento (BRASIL, 2019c). Já na versão publicada no DOU em janeiro de 2020, aparece a figura do Fundo de Investimento do Conhecimento, que é o nome dado ao "fundo de investimento privado constituído a partir da integralização de ativos." (BRASIL, 2020, art. $3^{\circ}$, XV). 0 projeto de lei autoriza a constituição, "no âmbito do Programa Future-se, de fundo patrimonial, observado o disposto na Lei $n^{\circ} 13.800$, de 4 de janeiro de 2019, com o objetivo de arrecadar, gerir e destinar doações de pessoas físicas e jurídicas privadas" (art. 27), assim como, no parágrafo único, autoriza a criação de outros fundos patrimoniais específicos para as universidades e institutos federais (BRASIL, 2020).

A Lei n. 13.800, de 4 de janeiro de 2019, que autoriza que a Administração Pública firme parcerias com organizações gestoras de fundos patrimoniais para execução de programas e projetos e que regula tal possibilidade (BRASIL, 2019a), teve origem após a Medida Provisória (MP) n. 851/2018 emitida pelo Ex-presidente Michel Temer. E, apoiado nesse dispositivo, o PL do Future-se, na V2, apresentava um rol taxativo, visto que, entre outras receitas possíveis, previa a cobrança de matrículas e mensalidades de pós-graduação lato sensu nas universidades e institutos federais (BRASIL, 2019c). Na V3 esse rol desaparece e não há previsão das formas possíveis de arrecadação de receitas, no entanto também não afasta a possibilidade de tal cobrança.

0 PL precisa ser analisado em sua base material de produção da vida, e o depauperamento das IFEs é um projeto para justificar maiores ataques, com o propósito de implementar, de forma facilitada, formas de gestão empresarial ao prometer eficiência e solução dos problemas. Como bem defendido por Peroni e Carvalho (2019), há uma evidente disputa de grandes corporações empresariais, com claro suporte de setor financeiro, pela apropriação dos fundos públicos e na direção da educação pública brasileira.

Caminhando para o fim, o PL traz em suas disposições finais a alteração expressa de, pelo menos, sete ${ }^{12}$ leis, dentre elas a Lei de Diretrizes e Bases da Educação Nacional (Lei n. 9.394/1996). A proposta de alteração da LDB vem para permitir a revalidação e o reconhecimento, de forma simplificada, de diplomas de graduação e pós-graduação expedidos por universidades estrangeiras de alto desempenho ou universidades privadas (BRASIL, 2020, art. 31). 


\section{CONSIDERAÇÕES FINAIS}

Tendo presentes os propósitos deste texto, ao término das análises a que nos dispusemos a realizar, entendemos ser importante mencionar que o PL que institui o Programa Future-se consiste em um ataque à educação como direito social, conforme prevê o artigo $6^{\circ}$ da Constituição da República Federativa do Brasil, de 1988, e um ataque frontal às lutas pela democratização da educação que é, historicamente, pauta dos movimentos da classe trabalhadora. Foi e tem sido, a partir dessas lutas, que pequenos passos, mas importantes, foram dados no sentido de interpretar gradativamente o artigo 205 da CRFB/1988, que atribui ao Estado o papel de garantir o direito de todos à educação.

No lugar da valorização e atenção orçamentária às Instituições Federais e, portanto, públicas de Ensino, o atual governo federal, que propõe o Programa Future-se, plantou a narrativa de que o ensino superior está falido e precisa ser repensado para se aproximar do mercado e lógica capitalistas, convergindo com o fenômeno da mercadorização da educação. Resistir a políticas como o Programa Future-se e defender a construção e a implementação de políticas educacionais que viabilizem o direito à educação devem estar, hoje, mais do que nunca, alicerçadas em uma concepção de educação pública, integral, laica, gratuita, inclusiva, democrática e de qualidade socialmente referenciada. Entendemos que a lógica presente no Future-se está atravessada por ideologias de agravamento e de manutenção das desigualdades e de favorecimento do empresariado da educação comprometidos com os interesses do sistema produtivo capitalista, indo na contramão da perspectiva da educação como direito social.

Inserir o empreendedorismo como eixo principal do Programa remete à criação de mais uma política educacional, implantada pelo Estado a partir de demandas dos donos do capital, que difunde "ilações sobre a emergência da educação para o empreendedorismo e [...] consequentemente, submete a educação aos interesses econômicos." (BARBOSA; FERREIRA, 2015, p. 71). Nesta seara, precisamos estar atentos para descontruir expressões e categorias que constituem os discursos dominantes, como competência, resiliência, flexibilidade, colaborador, empregabilidade, desemprego como oportunidade, etc. e recuperar e reiterar outras, como exploração, opressão, dominação, luta de classes, emprego e direitos (BARBOSA FERREIRA, 2015).

A internacionalização, também como eixo central do Programa, remete, pela totalidade do projeto, à transnacionalização e está relacionada a processos de mercadorização da educação superior (AZEVED0, 2015). Desse modo, corrobora com os fundos de investimento e patrimoniais trazidos no texto, que implantam, nas Universidades e nos Institutos Federais, 
lógicas do setor financeiro, afastando-os de sua função social, finalidades e características precípuas de formação humana, para além do capital.

A grave ameaça à autonomia didático-científica, administrativa e de gestão financeira e patrimonial das IFEs também precisa ser denunciada. Passamos pela transferência de atividades de gestão a uma Organização Social (entidade privada), pelos eixos que alterarão matrizes curriculares de cursos para inserir conteúdos que convirjam com a política do Programa, pelo contrato de resultados exigidos pelo Ministério da Educação, até a figura do comitê gestor, que inviabilizará qualquer autonomia, uma vez que os resultados esperados pelos financiadores das pesquisas e dos produtos darão o tom da "supervisão".

Por fim, os estudos realizados em torno do Programa Future-se nos permitem afirmar que suas intencionalidades, combinadas com as ameaças a outros direitos sociais, historicamente conquistados, são instrumentos que corroboram a conformação do projeto societário do capital. Nosso papel, enquanto estudantes, professores, gestores da educação superior pública e da sociedade brasileira em geral é construir movimentos de resistência que possam conter os retrocessos que ferem a autonomia das IFEs, seu papel social, suas finalidades e, com isso, o direito social à educação.

\section{REFERÊNCIAS}

ARAUJO, R. M. de L. Ensino médio brasileiro: dualidade, diferenciação escolar e reprodução das desigualdades sociais. Uberlândia: Navegando Publicações, 2019.

AZEVEDO, M. L. N. de. Transnacionalização e mercadorização da educação superior: examinando alguns efeitos colaterais do capitalismo acadêmico (sem riscos) no Brasil - A expansão privado-mercantil. Revista Internacional de Educação Superior, Campinas, v. 1, n. 1, p. 86-102, jul./set. 2015. Disponivel em: https://periodicos.sbu.unicamp.br/ojs/index.php/riesup/article/view/8650522. Acesso em: 13 dez. 2019.

BARBOSA, l.; FERREIRA, F. I. A "máquina do empreendedorismo": Teatro do Oprimido e educação crítica em tempo de crise. Investigar em Educação, Portugal, v. 2, n. 3, p. 63- 77, 2015. Disponível em: http:// pages.ie.uminho.pt/inved/index.php/ie/article/view/88/87. Acesso em: 15 jan. 2020.

BRASIL. Constituição. República Federativa do Brasil de 1988. Brasília, DF: Senado Federal, 5 out. 1988. Disponivel em: http://www.planalto.gov.br/ccivil_03/constituicao/constituicaocompilado.htm. Acesso em: 10 dez. 2019.

BRASIL. Decreto n. 9.269, de 24 de janeiro de 2018. Altera o Decreto $n^{\circ} 7.485$, de 18 de maio de 2011, que dispõe sobre a constituição de banco de professor-equivalente das universidades federais vinculadas ao Ministério da Educação e regulamenta a admissão de professor substituto, de que trata o inciso IV do art. $2^{\circ}$ da Lei ${ }^{\circ}{ }^{\circ} 8.745$, de 9 de dezembro de 1993. Diário Oficial da União, Brasília, DF, 25 jan. 2018. 
BRASIL. Emenda Constitucional n. 95, de 15 de dezembro de 2016. Altera o Ato das Disposições Constitucionais Transitórias, para instituir o Novo Regime Fiscal, e dá outras providências. Diário Oficial da União, Brasilia, DF 15 dez. 2016. Disponível em: http://www.planalto.gov.br/ccivil_03/constituicao/ emendas/emc/emc95.htm. Acesso em: 10 dez. 2019.

BRASIL. Lei n. 9.637, de 15 de maio de 1998. Dispõe sobre a qualificação de entidades como organizações sociais, a criação do Programa Nacional de Publicização, a extinção dos órgãos e entidades que menciona e a absorção de suas atividades por organizações sociais, e dá outras providências. Diário Oficial da União, Brasília, DF, 16 maio 1998. Disponível em: http://www.planalto.gov.br/ccivil_03/leis/ 19637.htm. Acesso em: 13 dez. 2019.

BRASIL. Lei n. 13.800, de 4 de janeiro de 2019. Autoriza a administração pública a firmar instrumentos de parceria e termos de execução de programas, projetos e demais finalidades de interesse público com organizações gestoras de fundos patrimoniais; altera as Leis $n^{\circ}$ s 9.249 e 9.250, de 26 de dezembro de 1995, 9.532, de 10 de dezembro de 1997, e 12.114 de 9 de dezembro de 2009; e dá outras providências. Diário Oficial da União, Brasília, DF, 21 jun. 2019a. Disponível em: http://www.planalto.gov. br/ccivil_03/_Ato2019-2022/2019/Lei/L13800.htm. Acesso em: 15 ago. 2019.

BRASIL. Ministério da Educação. Censo da Educação Superior 2017: divulgação dos principais resultados. Brasilia, DF: MEC; INEP, 2018. Disponivel em: http://portal.mec.gov.br/index.php?option=com_ docman\&view=download\&alias=97041-apresentac-a-o-censo-superior-u-ltimo\&category_ slug=setembro-2018-pdf\&ltemid=30192. Acesso em: 15 ago. 2019.

BRASIL. Ministério da Educação. Projeto de Lei de 2019. Institui o Programa Institutos e Universidades Empreendedoras e Inovadoras - FUTURE-SE, e dá outras providências. (Versão 1). Disponível em: https://www.cgee.org.br/documents/10195/734063/Programa+Future-se/c762b108-c424-4b03-8beef521e7c5e3f0? version=1.0 Acesso em: 13 ago. 2019b.

BRASIL. Ministério da Educação. Projeto de Lei de 2019. Institui o Programa Universidades e Institutos Empreendedores e lnovadores - Future-se, e dá outras providências. (Versão 2). Disponível em: http://estaticogl.globo.com/2019/10/16/minuta_de_anteprojeto_de_lei_futurese__gt_portaria_1701__16102019.pdf?_ga=2.255942539.105700768.1579370451-399226138.1524520246. Acesso em: 19 dez. 2019c.

BRASIL. Ministério da Educação. Projeto de Lei. Institui o Programa Universidades e Institutos Empreendedores e Inovadores - Future-se. (Versão 3). Diário Oficial da União, Brasília, DF, 3 jan. 2020. Disponivel em: http://www.in.gov.br/web/dou/-/despacho-236403674. Acesso em: 10 jan. 2020.

CATINI, C. Educação e empreendedorismo da barbárie. In: CASSIO, F. (org.). Educação contra a barbárie: por escolas democráticas e pela liberdade de ensinar. São Paulo: Boitempo, 2019.

INSTITUTO NACIONAL DE ESTUDOS E PESQUISAS EDUCACIONAIS ANISIO TEIXEIRA. Sinopse Estatística da Educação Superior 2002. Brasília, DF: INEP, 2002. Disponivel em: http://portal.inep.gov.br/web/guest/ sinopses-estatisticas-da-educacao-superior. Acesso em: 13 ago. 2019. 
INSTITUTO NACIONAL DE ESTUDOS E PESQUISAS EDUCACIONAIS ANISIOO TEIXEIRA. Sinopse Estatística da Educação Superior 2010. Brasilia, DF: INEP, 2010. Disponivel em: http://portal.inep.gov.br/web/guest/ sinopses-estatisticas-da-educacao-superior. Acesso em: 13 ago. 2019.

INSTITUTO NACIONAL DE ESTUDOS E PESQUISAS EDUCACIONAIS ANISIO TEIXEIRA. Sinopse Estatística da Educação Superior 2017. Brasilia, DF: INEP, 2017. Disponível em: http://portal.inep.gov.br/web/guest/ sinopses-estatisticas-da-educacao-superior. Acesso em: 13 ago. 2019.

KOSIK, K. A dialética do concreto. Tradução: Célia Neves e Alderico Toríbio. 2. ed. Rio de Janeiro: Paz e Terra, 1976.

KRAWCZYK, N.; FERRETTI, C. J. Flexibilizar pra quêe Meias verdades da "reforma". Retratos da Escola, Brasilia, DF, v. 11, n. 20, p. 33-44, jan./jun. 2017.

MARX, K. Prefácio à contribuição à crítica da economia política. In: MARX, K.; ENGELS, F. Marx e Engels, Obras Escolhidas, São Paulo: Editora Alfa-Ômega, 1986. v. 1. p. 300-303.

PERONI, V. M. V.; CARVALHO, E. J. G. de. A atuação do setor privado no planejamento e na execução das políticas sociais: implicações para a democratização educação. Teoria e Prática da Educação, Maringá, v. 22, n. 3, p. 1-4, set./dez. 2019. Disponivel em: http://periodicos.uem.br/ojs/index.php/TeorPratEduc/ article/view/51382. Acesso em: 20 dez. 2019.

SANTOS, D. A. 1990 - 2017: 0 projeto neoliberal e os programas de publicização: análise de algumas tendências para a Politica Social. In: JORNADA INTERNACIONAL POLITICAS PÚBLICAS, 8., 2017, São Luís. Anais [...] São Luis, 2017. Disponível em: http://www.joinpp.ufma.br/jornadas/joinpp2017/pdfs/eixo1/199 02017oprojetoneoliberaleosprogramasde.pdf. Acesso em: 14 ago. 2019.

SEKI, A. K.; SOUZA, A.; EVANGELISTA, 0. A formação docente superior: hegemonia do capital no Brasil. Retratos da Escola, Brasília, DF, v. 11, n. 21, p. 447-467, jul./dez. 2017. Disponível em: www.esforce.org.br Acesso em: 15 ago. 2019.

SILVA, M. R. da; SCHEIBE, L. Reforma do ensino médio: pragmatismo e lógica mercantil. Retratos da Escola, Brasilia, DF, v. 11, n. 20, p. 19-31, jan./jun. 2017.

SILVA, N. de M. e; TEIXEIRA, S. M. Trabalho e "questão social" no capitalismo contemporâneo: a política social capitalista e o fetiche do microempreendedorismo individual no Estado do Piauí. Revista de Políticas Públicas, São Luís, v. 19, n. 2, p. 625-632, jul./dez. de 2015. Disponível em: http://www.periodicoseletronicos.ufma.br/index.php/rppublica/article/view/4341/2405. Acesso em: 17 jan. 2020.

Endereço para correspondência: Rua Joaquim Garcia, s/n, Centro, Camboriú, Santa Catarina, Brasil; filomenarodriguesdasilva@yahoo.com.br

Roteiro, Joaçaba, U. 45, p. 1-20, jan./dez. 2020 | e23778 |E-ISSN 2177-6059 